\title{
Coordination Effect and Dynamic Relationship of Green Governance and Corporate Performance
}

\author{
Lin ZHANG and Ji WANG ${ }^{* 1}$ \\ School of Management, Shanghai University, Shanghai 200444, China
}

\begin{abstract}
This paper uses entropy method and coupling coordination model to empirically analyze the coupling coordination effect and dynamic relationship between green governance and corporate performance of listed manufacturing companies. The results show: (1) Green governance has shown a steady growth from 2009 to 2019, but it is still in its infancy. The overall governance index is low, and there is more room for improvement. (2) The relationship between green governance and corporate performance is fluctuating in the short term, but from a long-term perspective, they have a balanced development. With the improvement of green governance, the positive effects continue to expand, bringing more obvious economic effects in the long run. (3) The degree of coupling coordination between green governance and corporate performance has fluctuated upwards, and the coordinated development has been continuously optimized. However, green governance and corporate performance have not yet reached high coupling, showing a state of primary coordination.
\end{abstract}

Keywords. Green governance, corporate performance, coupling coordination model

\section{Introduction}

High energy consumption and pollution status is a severe challenge to the sustainable development of the economy and society [1]. When the existing governance theories and governance models are difficult to effectively respond to the great changes, the "greening" of governance follows the trend. The report of the 19th National Congress of the Communist Party of China pointed out that the economy is in a transitional stage from high-speed growth to high-quality growth [2,3]. It needs to meet the five basic concepts of "innovation, coordination, green, openness, and sharing", which highlights the importance of ecological environment [4]. As an advanced form of human production organization, enterprises are the main body of energy consumption and pollution emissions, and they bear the inescapable social responsibility for energy conservation, emission reduction, and environmental governance [5, 6].

Whether it is from current governance practices or academic research results, green governance remains in the mere rhetoric of government governance, and it obviously lacks systematic academic support [7]. The research on green governance mainly focuses on the definition of the connotation, governance capability and

\footnotetext{
${ }^{1}$ Corresponding Author, Ji WANG, School of Management, Shanghai University, Shanghai 200444, China; Email: 2013ridiculous@sina.com.
} 
realization path of government green governance. Enterprises are the main body of energy consumption and pollution emissions [8,9]. The implementation of a green governance system is not only an important path for enterprises to achieve sustainable development, but also an inescapable social responsibility of enterprises [10]. However, there are few studies on the coordination level and mechanism of corporate green governance and corporate performance at the micro level. Therefore, a systematic review of corporate green governance and research on the coordination effect of the two system are of great significance to China's promotion of green development and green governance.

\section{Research Methods and Model Construction}

We selected A-share manufacturing listed companies (industry codes C13-C43) that continuously disclosed independent social responsibility reports from 2009 to 2019 as the research object. There are 206 companies in 11 years with a total of 2266 data points. The data on green governance mainly comes from the social responsibility reports. Enterprise performance (Return on Assets, ROA) comes from the CSMAR database.

\subsection{Comprehensive Evaluation Model}

We suppose $\mu_{i j}$ is the standardized value. $\mu_{i j}$ and $\beta_{i j}$ are the upper and lower limits (namely the maximum and minimum) of the sequence parameters. Then the orderly efficiency coefficient of the coupling system of green governance and corporate performance can be expressed as:

$$
\mu_{i j}= \begin{cases}\left(X_{i j}-\beta_{i j}\right) /\left(\alpha_{i j}-\beta_{i j}\right) & \mu_{i j} \text { is a positive indicator } \\ \left(\alpha_{i j}-X_{i j}\right) /\left(\alpha_{i j}-\beta_{i j}\right) & \mu_{i j} \text { is a negative indicator }\end{cases}
$$

We use linear weighted summation method to achieve integration, the formula is:

$$
\begin{gathered}
U_{i}=\sum_{j=1}^{n} \lambda_{i j} \mu_{i j} \\
\sum_{j=1}^{n} \lambda_{i j}=1, \lambda_{i j} \geq 0
\end{gathered}
$$

where $U_{i}$ represents the contribution of the subsystem to the overall system; $\lambda_{i j}$ represents the weight of the subsystem, which is determined by the entropy weighting method. 


\subsection{Coupling Coordination Model and Classification}

The calculation method of coupling degree is:

$$
C=\left\{\frac{U_{1} U_{2}}{\left[\left(U_{1}+U_{2}\right) / 2\right]^{2}}\right\}^{2}
$$

where $U_{1}$ and $U_{2}$ respectively represent the comprehensive evaluation results. To further measure the degree of coupling and coordination between the two, the formula is as follows:

$$
\begin{aligned}
& T=\alpha U_{1}+\beta U_{2} \\
& D=\sqrt{C^{*} T}
\end{aligned}
$$

where $\alpha$ and $\beta$ represent undetermined coefficients $(\alpha+\beta=1)$, which respectively represent the importance of green governance and corporate performance in the entire system ( $\alpha=\beta=0.5$ ) [11]. The value range of coupling coordination degree $\mathrm{D}$ is [0, 1], the larger the value, the higher the degree of coordinated development between green governance and corporate performance.

\subsection{Index System}

This study sets 23 evaluation indicators from five dimensions of green culture, green mechanism, green production, green efficiency, and green responsibility to describe the level of corporate green governance, as shown in table 1. Enterprise performance data is measured by the ROA (Return on Assets) [12].

\section{Analysis and Results}

\subsection{Comprehensive Score of Green Governance}

According to the index weight, the comprehensive index, and various sub-indexes of corporate green governance from 2009 to 2019 are obtained. The comprehensive evaluation value of the green governance is shown in figure 1.

In general, the level of corporate green governance has shown a continuous growth trend from 2009 to 2019, indicating that as the importance of ecological construction has become increasingly prominent, corporate green governance has also been valued and improved. Among them, 2010-2015 is a period of rapid growth, and 2016-2019 remains stable and fluctuating.

\subsection{Coupling Coordination Degree of Green Governance and Corporate Performance}

Table 2 shows the coupling and coordination degree of the manufacturing industry from 2009 to 2019. From 2009 to 2013, the manufacturing industry was in a high- 
level coupling stage. From 2009 to 2019, the green governance and corporate performance have achieved considerable development, but the coordination between the two still needs to be improved $(\mathrm{D}<0.7)$.

Table 1. Evaluation index system for corporate green governance.

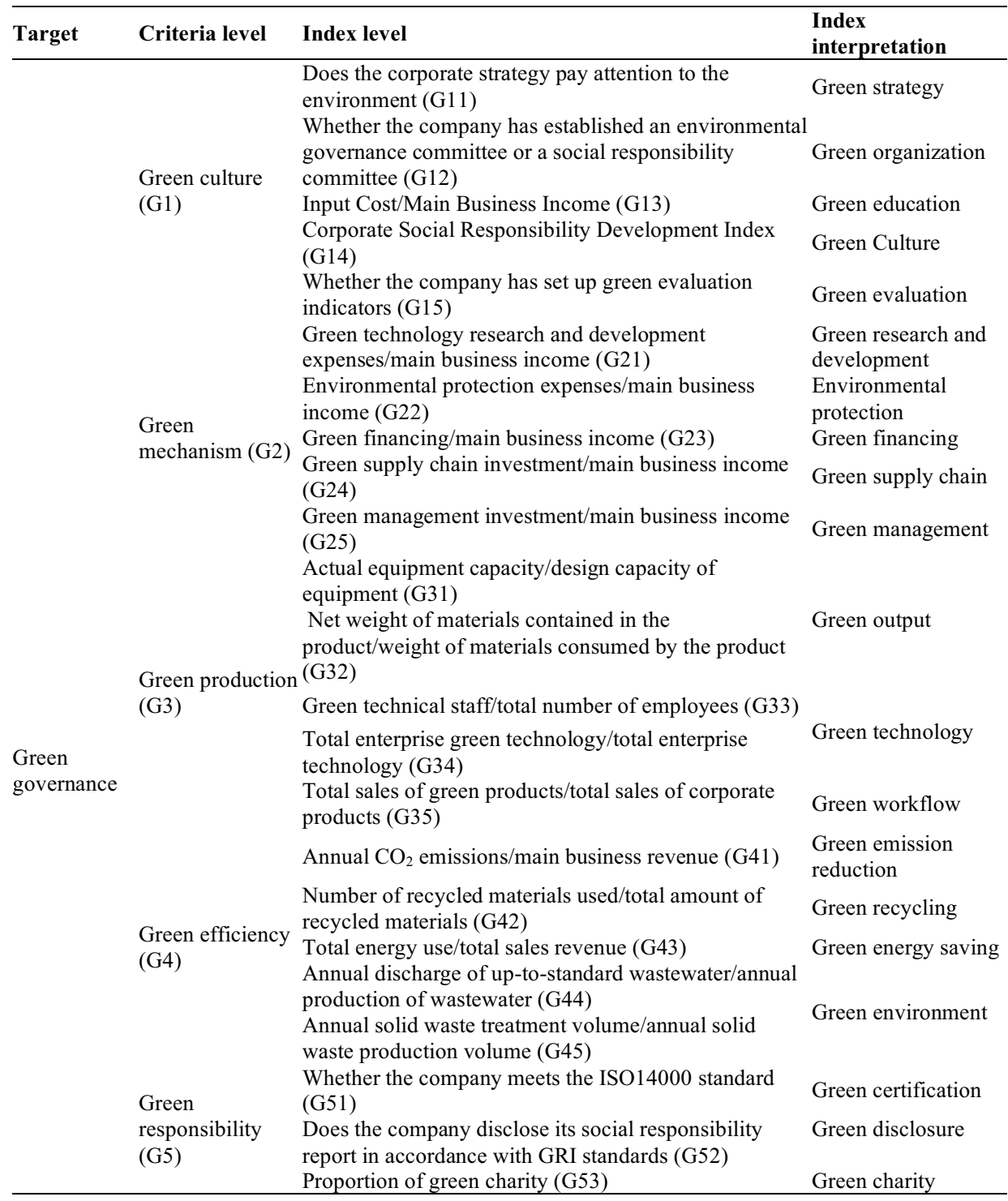




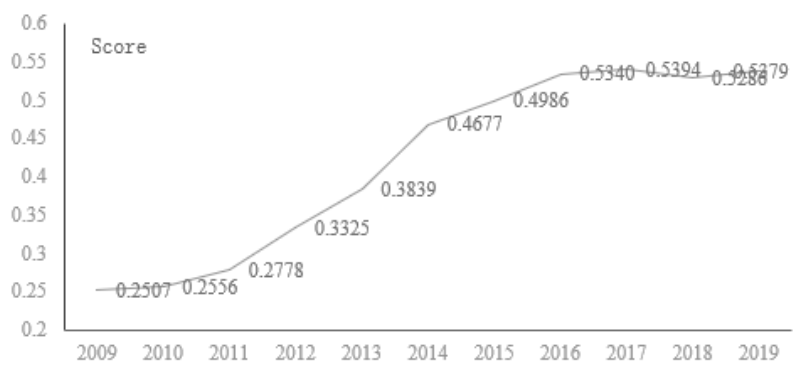

Figure 1. Comprehensive scores of green governance.

Table 2. Overall coupling and coordination results.

\begin{tabular}{llll}
\hline Year & Coupling (C) & Coupling coordination (D) & Coordination type \\
\hline 2009 & 0.842 & 0.506 & Barely coordinated \\
2010 & 0.835 & 0.481 & On the verge of out-of-tune \\
2011 & 0.869 & 0.481 & On the verge of out-of-tune \\
2012 & 0.939 & 0.544 & Barely coordinated \\
2013 & 0.866 & 0.549 & Barely coordinated \\
2014 & 0.799 & 0.580 & Barely coordinated \\
2015 & 0.786 & 0.605 & Primary coordinated \\
2016 & 0.810 & 0.652 & Primary coordinated \\
2017 & 0.853 & 0.682 & Primary coordination \\
2018 & 0.847 & 0.666 & Primary coordination \\
2019 & 0.842 & 0.673 & Primary coordination \\
\hline
\end{tabular}

\subsection{Dynamic Relationship between Green Governance and Corporate Performance}

\subsubsection{Unit Root Test}

In order to eliminate the randomness between the sample data and avoid the phenomenon of "false regression", we adopt the unit root test of panel data [13]. The results are shown in table 3. It can be seen in table 3 that the first-order difference of the three variables is stable.

Table 3. Unit root test results of panel data.

\begin{tabular}{lllll}
\hline Variable & LLC test & HT test & IPS test & Fisher-ADF test \\
\hline Green & -0.7195 & $0.4655^{* * *}$ & $-3.1291 * * *$ & $29.1979 * *$ \\
$\Delta$ Green & $-3.0519 * *$ & $-0.4642 * * *$ & $-2.9562 * * *$ & $28.6824 * *$ \\
Performance & $-1.4614 *$ & 0.8913 & -0.6058 & 3.6866 \\
$\Delta$ Performance & $-4.0280 * * *$ & $0.2980 * * *$ & $-1.9864 *$ & $-1.5150 *$ \\
\hline
\end{tabular}

Note: $* * *$ and $* * *$ indicate that the significance test of $10 \%, 5 \%$ and $1 \%$ has been passed.

\subsubsection{Cointegration Test}

The co-integration test in this part adopts the Kao co-integration test method, and the results are shown in table 4 . Table 4 shows that the $\mathrm{P}$ value of the cointegration test is $0.0471(\mathrm{P}<0.05)$, which shows that there is a co-integration relationship between green governance and corporate performance. 
Table 4. Kao cointegration test results.

\begin{tabular}{lll}
\hline Variable & Statistic & $\mathbf{P}$ \\
\hline Green \& Performance & -1.6735 & 0.0471 \\
\hline Note: $* * *$ and $* * *$ & indicate that the significance test of $10 \%, 5 \%$ and $1 \%$ has been passed.
\end{tabular}

\subsubsection{Analysis of Variance Decomposition}

Variance decomposition is used to analyze the contribution of the impact of each unit to the prediction variance, and the results are shown in table 5 .

Table 5. Variance decomposition results.

\begin{tabular}{lllll}
\hline \multirow{2}{*}{ Periods } & \multicolumn{4}{l}{ Variance decomposition of green governanceVariance decomposition of corporate performance } \\
\cline { 2 - 5 } & Green governance & Corporate performance & Green governance & Corporate performance \\
\hline 1 & 0.937865 & 0.062135 & 0 & 1 \\
2 & 0.91562 & 0.08438 & 0.004558 & 0.995442 \\
3 & 0.873937 & 0.126063 & 0.032344 & 0.967656 \\
4 & 0.845658 & 0.154342 & 0.061095 & 0.938905 \\
5 & 0.836194 & 0.163806 & 0.074845 & 0.925155 \\
6 & 0.835338 & 0.164662 & 0.078293 & 0.921707 \\
7 & 0.83586 & 0.16414 & 0.078494 & 0.921506 \\
8 & 0.835909 & 0.164091 & 0.078458 & 0.921542 \\
\hline
\end{tabular}

In the variance decomposition of green governance, the impact of green governance contributed the most to its own forecast variance. The contribution of the first period was $93.7865 \%$, and then it continued to decline. The impact was revealed in the first period $(6.2135 \%)$, then slowly increased to $16.4662 \%$ in the sixth period. It shows that green governance of the manufacturing industry has a timely, fluctuating and continuous impact on corporate performance. With the improvement of green governance, the positive effects continue to expand, internally improve the corporate operating mechanism.

In the variance decomposition of corporate performance, the impact of corporate performance on the forecast variance contribution of green governance only began to appear in the second period. The initial contribution (the second period) was the lowest $(0.4558 \%)$, and then continued to increase steadily, and reached the maximum value of $7.8494 \%$ in the seventh period. Corporate performance of the manufacturing industry has a lagging and continuous impact on green governance.

\section{Conclusion}

This study selects A-share manufacturing listed companies that continuously disclosed independent social responsibility reports from 2009 to 2019 as the research object, constructs a comprehensive evaluation index system for green governance, analyzes the time series evolution and the dynamic interaction process. Green governance has shown a steady growth from 2009 to 2019 , but it is still in its infancy. The overall governance index is low, and there is more room for improvement. 
The relationship between green governance and corporate performance is fluctuating in the short term, but from a long-term perspective, they have a balanced development trend. With the improvement of green governance, the positive effects continue to expand. In the short term, it may lead to increased costs, but in the long term it will bring more obvious economic effects and promote the growth of corporate performance. The coupling and coordination degree between green governance and corporate performance has fluctuated upward, and the coupling and coordination development has been continuously optimized. However, at present, the green governance and corporate performance have not yet reached the benign resonance of high coupling, showing a state of primary coupling and coordination.

\section{References}

[1] Bhattacharya S and Sharma D 2019 Social and governance performance impact credit ratings International Journal of Ethics and Systems 35 466-484.

[2] Hanninen N and Karjaluoto H 2017 Environmental values and customer-perceived value in industrial supplier relationships Journal of Cleaner Production 156 604-613.

[3] Hawn O 2021 How media coverage of corporate social responsibility and irresponsibility influences cross-border acquisitions Strategic Management Journal 42 58-83.

[4] Jacobs B, Kraude R and Narayanan S 2016 Operational Productivity, Corporate Social Performance, Financial Performance, and Risk in Manufacturing Firms Production and Operations Management 25 2065-2085.

[5] Petljak K, Zulauf K, Stulec I, Seuring S and Wagner R 2018 Green supply chain management in food retailing: survey-based evidence in Croatia Supply Chain Management-An International Journal 23 115.

[6] Phillips T, Woods C and Lythberg B 2016 An investigation into the aspirations, governance and management challenges of Maori farming trusts Outlook on Agriculture 45 246-253.

[7] Qian W and Schaltegger S 2017 Revisiting carbon disclosure and performance: Legitimacy and management views British Accounting Review 49 365-379.

[8] Salhieh L and Abushaikha I 2016 Assessing the driving forces for greening business practices South African Journal of Business Management 47 59-69.

[9] Ormond J 2020 Geoengineering super low carbon cows: food and the corporate carbon economy in a low carbon world Climatic Change 163 135-153.

[10] Passetti E, Cinquini L and Tenucci A 2018 Implementing internal environmental management and voluntary environmental disclosure: Does organisational change happen Accounting Auditing \& Accountability Journal 31 1145-1173.

[11] Pavaloaia L, Carp M and Georgescu I 2018 Sustainability reporting and investor reaction: Evidence from the Romanian capital market Transformations in Business \& Economics 17 806-822.

[12] Boakye D, Tingbani I, Ahinful G, Damoah I and Tauringana V 2020 Sustainable environmental practices and financial performance: Evidence from listed small and medium-sized enterprise in the United Kingdom Business Strategy and the Environment 29 2583-2602.

[13] Cancela B, Neves M, Rodrigues L and Dias A 2020 The influence of corporate governance on corporate sustainability International Journal of Accounting and Information Management 28 785-806. 